\title{
DC resistivity of alumina and zirconia sintered with $\mathrm{TiC}$
}

\author{
DIBYENDU CHAKRAVARTY ${ }^{\dagger}$, SOUMYADIP ROY ${ }^{\dagger}$ and PROBAL K DAS* \\ Central Glass and Ceramic Research Institute, Kolkata 700 032, India \\ College of Ceramic Technology, Kolkata 700 010, India
}

MS received 20 October 2003; revised 11 February 2005

\begin{abstract}
Pure alumina and zirconia powders were sintered separately with increasing amount of TiC up to $\sim 65 \mathrm{vol} . \%$, as a conducting second phase with an aim to prepare conducting structural ceramics which can be precisely machined by EDM technique. TiC did not help in sintering the parent phase but it decreased the d.c. resistivity of the composite to $1 \mathrm{ohm} . \mathrm{cm}$ at $\sim 30$ vol.\% loading. The conductivity is explained by the effective media and percolation theories.
\end{abstract}

Keywords. Alumina; zirconia; titanium carbide; composite; electrical conductivity; electrical resistivity.

\section{Introduction}

Attempts have been made in different directions to improve the mechanical properties of the structural ceramics. Promising among them is a second phase reinforcement in the parent matrix. The ceramics of superior mechanical properties in turn give rise to time consuming finishing processes which are quite expensive. As a solution to this problem, a newer technique of finishing the components at a faster rate and at a relatively reduced cost viz. electro discharge machining (EDM) technique, has been applied in some cases. The technique essentially needs the components to be electrically conducting (resistance $<100$ ohm-cm). The electrically conducting and compatible second phase materials such as nitrides (TiN), borides $\left(\mathrm{TiB}_{2}\right)$, carbides $(\mathrm{TiC})$ and silicides $\left(\mathrm{MoSi}_{2}, \mathrm{Ti}-\mathrm{Si}\right)$, the electrical resistivity of which are in the range of $13-50 \times$ $10^{-6} \mathrm{ohm}-\mathrm{cm}$, may impart conductivity to the matrix. The reinforcing second phase may also improve mechanical properties of the material. The electrical conductivity of the matrix is directly dependent on the size and amount of the conducting second phase grains, in general (Pierson 1996).

Research in this direction was carried out mainly with engineering ceramics like $\mathrm{Si}_{3} \mathrm{~N}_{4}, \mathrm{SiC}$ etc (Matkin et al 1972; Bellosi et al 1989; Mclachlan et al 1990; Sawaguchi et al 1991; Nakayama and Kuroshima 1992). $\mathrm{Si}_{3} \mathrm{~N}_{4}$ when sintered with SiC nanoparticle (Sawaguchi et al 1991) reduced the resistivity of the composite-the effect was remarkable above $10 \% \mathrm{SiC}$. Resistance with $25 \% \mathrm{SiC}$ was found to be $\sim 1 \times 10^{7} \Omega \mathrm{cm}$ and the composite behaved like a semiconductor. The critical volume of $\mathrm{SiC}$ at the boundaries of sintered $\mathrm{Si}_{3} \mathrm{~N}_{4}$ grains was $17 \%$ and the

\footnotetext{
*Author for correspondence (probal@cgcri.res.in)
}

electrical behaviour of the composite followed the percolation theory. Up to $10 \% \mathrm{SiC}$ increased the fracture toughness of the composite. $\mathrm{Si}_{3} \mathrm{~N}_{4}$ sintered with $\mathrm{TiN}$ (Nakayama and Kuroshima 1992) without any other additive reduced impedance of the composite from $\sim 1 \times$ $10^{7} \Omega \mathrm{cm}$ to $\sim 1 \times 10^{3} \Omega \mathrm{cm}$ when measured in the presence of moisture. A lot of work was done on $\mathrm{SiC}$ based material as the use of $\mathrm{SiC}$ in electrical/electronic devices is wide, e.g. making heating elements, semiconductors, sensors, varistors, etc. $\mathrm{Al}_{2} \mathrm{O}_{3}$ and $\mathrm{ZrO}_{2}$ are two other common structural engineering ceramic materials. Scanty reports are available on increasing electrical conductivity of the materials (Guicciardi 1992; Buerger 1994; Krell et al 1995; Mao et al 1998; Wang et al 1998) or in the related field. Mao and co-workers (1998) worked on cobalt coated $\mathrm{Al}_{2} \mathrm{O}_{3}-\mathrm{TiC}$ composite and measured only the abrasion resistance of the composite. They showed that the role of cobalt coating was important and it was responsible for wear damage. Buerger (1994) used up to 50 wt.\% TiC with $\mathrm{Al}_{2} \mathrm{O}_{3}$. DC resistivity decreased from $1 \times 10^{12}$ to $\sim 1 \times 10^{-3} \Omega \mathrm{cm}$ with $45 \% \mathrm{TiC}$. The conductivity was explained by the model of connectivity of TiC particles. TiC, up to $30 \mathrm{wt} \%$, increased flexural strength of the composite. Krell and co-workers (1995) used 30\% TiC with $\mathrm{ZrO}_{2}$ with or without $\mathrm{TiH}_{2} . \mathrm{TiH}_{2}$ changed the stoichiometry of $\mathrm{TiC}$ in the sintered matrix. The grains were free from amorphous phase; the strength and toughness of the composite was similar to 3Y-TZP. Bellosi and co-workers (1989) studied in detail the $\mathrm{Al}_{2} \mathrm{O}_{3}$ based composites. They used 20 and 30 vol. $\%$ of $\mathrm{TiC} / \mathrm{TiN}$ or $\mathrm{TiB}_{2}$ and measured the CTE, E-modulus, Vicker's hardness at $500 \mathrm{~g}$ load, fracture toughness, flexural strength up to $800^{\circ} \mathrm{C}$, oxidation resistance and d.c. electrical resistivity. The effect of $\mathrm{TiN}$ on the above mentioned properties is more compared to the others. However, oxidation resistance of the composites is poor above $800^{\circ} \mathrm{C}$. DC resis- 
tivity decreases to $\sim 10^{-3} \mathrm{ohm} \cdot \mathrm{cm}$ with 30 vol. $\% \mathrm{TiN}$ and the threshold percolation volume is below 20 vol. $\%$. They inferred that the composite may be machined by EDM technique. Wang and co-workers (1999) reported on d.c. resistivity of $\mathrm{Si}_{3} \mathrm{~N}_{4}-\mathrm{TiC}$ composite and their mechanical properties. They explained the conductivity through percolation theory and calculated the threshold loading of $\mathrm{TiC}$ for conductivity to be $18.5 \mathrm{vol} . \%$.

An attempt has been made in this work to study the d.c. electrical behaviour of pure $\mathrm{Al}_{2} \mathrm{O}_{3}$ and $\mathrm{ZrO}_{2}$ with addition of $\mathrm{TiC}$ and also to optimize the amount of $\mathrm{TiC}$ addition. Relevance of decrease of d.c. resistivity of $\mathrm{ZrO}_{2}$ and $\mathrm{Al}_{2} \mathrm{O}_{3}$ with $\mathrm{TiC}$ was explained with the help of effective media and percolation theories.

\section{Experimental}

Pure $\mathrm{Al}_{2} \mathrm{O}_{3}$ (HTM30, 99.5\%, avg. particle size, $5 \mu \mathrm{m}$, Indian Aluminium Co., Kolkata), pure $\mathrm{ZrO}_{2}$ (99.9\%, avg. particle size, $10 \mu \mathrm{m}$, Indian Rare Earths Ltd., Thiruvananthapuram) and $\mathrm{TiC}(99.0 \%$, avg. particle size, $16 \mu \mathrm{m}$, H.C. Starck, Goslar, Germany) were taken for preparation of the composites. Each composition (table 1) was mixed in pure isopropyl alcohol for $3 \mathrm{~h}$. The pellets of $18 \mathrm{~mm}$ diameter were dry pressed uniaxially at $300 \mathrm{MPa}$ and sintered at $1600^{\circ} \mathrm{C}$ in pure argon in a graphite resistance heated furnace for 10, 30, 90 and 180 min. Bulk density of the sintered pellets were measured by water displacement method. X-ray diffractograph of the samples were taken to detect the major phases and to know if there was any reaction. The samples with low porosity were polished progressively with $60 \mu \mathrm{m}, 10 \mu \mathrm{m}, 6 \mu \mathrm{m}$, $3 \mu \mathrm{m}$ and $1 \mu \mathrm{m}$ diamond paste for microstructural study. The ground pellets were coated with silver paint, cured and their d.c. resistivity was measured with a precision ohm-meter (Hewlett Packard Resistance Tester) at room temperature.

\section{Results and discussion}

\subsection{Sintering}

Sintered density of both $\mathrm{Al}_{2} \mathrm{O}_{3}$ and $\mathrm{ZrO}_{2}$ composites with varying percentages of $\mathrm{TiC}$ was measured and is plotted in figure 1 . The density is compared with the theoretical density of the composites calculated using mixture rule. Sintered density of the composites achieved in the case of $\mathrm{Al}_{2} \mathrm{O}_{3}(0 \% \mathrm{TiC}$ ) based composition is $78 \%$ ( $\max .80 \%$ ) while that in the case of $\mathrm{ZrO}_{2}(0 \% \mathrm{TiC})$ is $73 \%$ because of poorer sinterability of $\mathrm{ZrO}_{2}$ compared to $\mathrm{Al}_{2} \mathrm{O}_{3}$ at $1600^{\circ} \mathrm{C}$ (even in $180 \mathrm{~min}$ ). Sintering of alumina with $\mathrm{TiC}$ addition is, however, poor and the average density reduces to $67 \%$ compared to the theoretical value at 55 vol. $\%$ TiC. The average sintered density in the case of $\mathrm{ZrO}_{2}-\mathrm{TiC}$ composites measured over the whole range of TiC addition is $\sim 73 \%$ while that with $\mathrm{Al}_{2} \mathrm{O}_{3}$ drops down slowly with increase of $\mathrm{TiC}$ content and achieves an average value of $67 \%$ at 55 vol. $\%$ TiC content in the composites. $\mathrm{TiC}$ in both cases acts as an inert phase and it does not react with the parent phase. TiC acts detrimentally with alumina in forming the composites. The SEM photomicrographs of the composites with 25.68 vol.\% TiC-alumina and 33.75 vol.\% TiC-zirconia are shown in figures $2 \mathrm{a}$ and $\mathrm{b}$. The second phase was seen to be evenly dispersed in the matrix. XRD result shows no reaction between the matrix and the second phase.

\subsection{DC electrical resistivity}

Figure 3 shows the reduction of d.c. resistivity of the composites with amount of TiC. The fall of resistivity of the composites is similar in nature which reaches a plateau after a critical percolation volume of TiC. The composites sintered for $180 \mathrm{~min}$ had the critical volume of inflexion of resistivity $\left(\varphi_{c}\right)$ at 34.0 and $26.3 \mathrm{vol} \%$ for $\mathrm{ZrO}_{2}$ and $\mathrm{Al}_{2} \mathrm{O}_{3}$, respectively. The fall in d.c. resistivity is sharp for the composites sintered for shorter time and the critical percolation volume is also low compared to the others. Sintering within such a short time is very poor and the fine TiC particles are also well distributed in the matrix, while the composites sintered for longer time shows more coagulation of $\mathrm{TiC}$ in the matrix. Hence the critical percolation volume is more although the matrix is denser than the former. From the microstructures of $\mathrm{Al}_{2} \mathrm{O}_{3}-\mathrm{TiC}$ it is obvious that $\mathrm{TiC}$ is more dispersed in the matrix and the effect is reflected in the $\varphi_{c}$ values. The d.c. resistivity reduced to $1 \Omega \mathrm{cm}$ which is favourable for machining the matrix by EDM technique.

Table 1. Batch composition.

\begin{tabular}{lccccccc}
\hline Sample & Wt.\% $\mathrm{Al}_{2} \mathrm{O}_{3}$ & $\mathrm{Wt} . \% \mathrm{TiC}$ & $\mathrm{Vol} . \% \mathrm{TiC}$ & Sample & $\mathrm{Wt} . \% \mathrm{ZrO}_{2}$ & Wt.\% TiC & Vol.\% TiC \\
\hline $\mathrm{A}_{0}$ & 100 & 0 & 0 & $\mathrm{Z}_{0}$ & 100 & 0 & 0 \\
$\mathrm{~A}_{1}$ & 90 & 10 & $8 \cdot 17$ & $\mathrm{Z}_{1}$ & 90 & 10 & $11 \cdot 72$ \\
$\mathrm{~A}_{2}$ & 80 & 20 & $16 \cdot 67$ & $\mathrm{Z}_{2}$ & 80 & 20 & $23 \cdot 02$ \\
$\mathrm{~A}_{3}$ & 70 & 30 & $25 \cdot 68$ & $\mathrm{Z}_{3}$ & 70 & 30 & $33 \cdot 75$ \\
$\mathrm{~A}_{4}$ & 60 & 40 & 34.99 & $\mathrm{Z}_{4}$ & 60 & 40 & $44 \cdot 32$ \\
$\mathrm{~A}_{5}$ & 50 & 50 & $44 \cdot 67$ & $\mathrm{Z}_{5}$ & 50 & 50 & $54 \cdot 43$ \\
$\mathrm{~A}_{6}$ & 40 & 60 & $54 \cdot 77$ & $\mathrm{Z}_{6}$ & 40 & 60 & $64 \cdot 19$ \\
\hline
\end{tabular}


The d.c. resistivity of the composites may be explained with the help of percolation theory which explains the conductivity of a composite medium near a metal-insulator transition region. This theory applies, in a strict sense, only when conductivity of the low conducting phase is zero or resistivity of the high conducting phase is zero (Wang et al 1999) ideally. In a real case, the general effective media (GEM) equation has been postulated (Mclachlan 1988) where conductance of both media $\left(\sigma_{\mathrm{h}}\right.$ and $\sigma_{1}$ ) is finite occurrence thus overcoming the limitation of the percolation theory. The equation fits accurately the conductivity for a large number of binary composite media.

In a continuous medium, comprising of an insulating medium as the parent matrix and an electrically conducting second phase, percolation theory predicts that near a conductor-nonconductor transition of the matrix, the resistivity will be given by the percolation equation

$$
\rho_{\mathrm{m}}=k\left\{(1-\varphi) / \varphi_{\mathrm{c}}\right\}^{\mathrm{t}}
$$

where $\rho_{\mathrm{m}}$ is the total resistivity of the composite, $\varphi$ the volume fraction of high conductivity phase, $\varphi_{c}$ the criti-
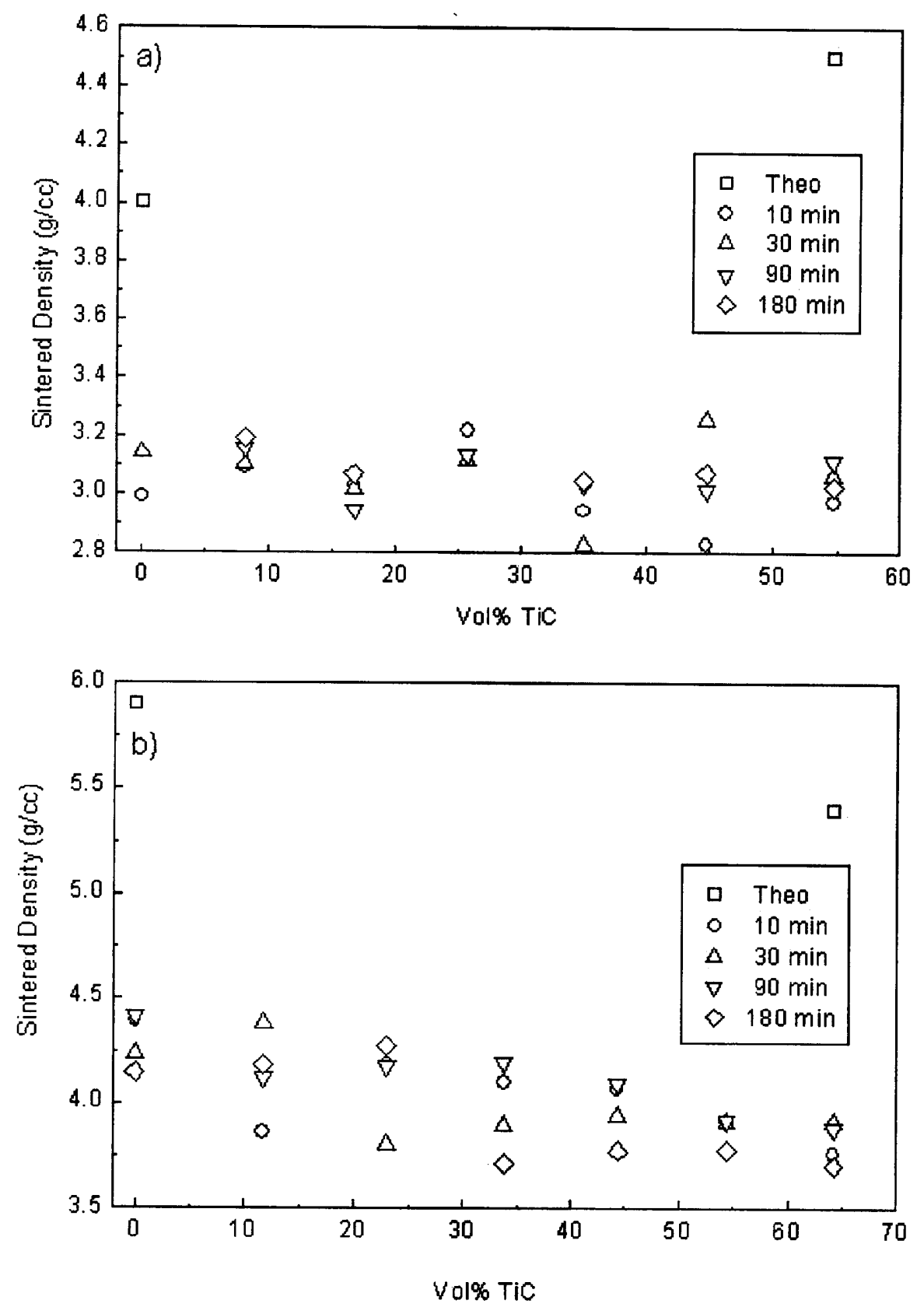

Figure 1. Variation of sintered density of (a) $\mathrm{Al}_{2} \mathrm{O}_{3}-\mathrm{TiC}$ and (b) $\mathrm{ZrO}_{2}-\mathrm{TiC}$ with amount of TiC sintered at $1600^{\circ} \mathrm{C}$ at different soaking times. 

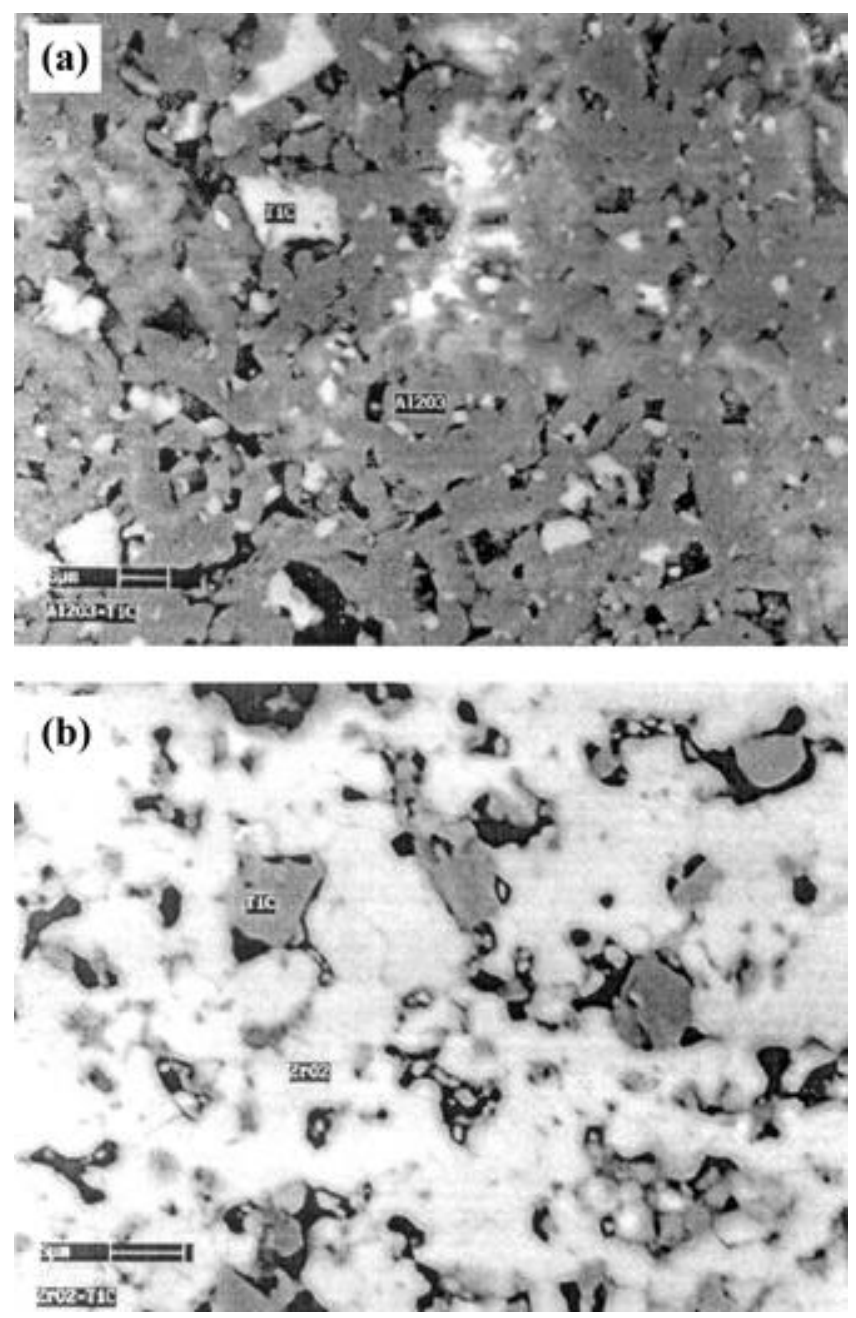

Figure 2. SEM micrograph of (a) $74 \cdot 3 \mathrm{Al}_{2} \mathrm{O}_{3}-25 \cdot 7$ vol.\% TiC composite and (b) $66.25 \mathrm{ZrO}_{2}-33.75$ vol.\% TiC composite.

Table 2. Values of threshold percolation volume $\left(\varphi_{\mathrm{c}}\right)$ and $t$ of the composites.

\begin{tabular}{lccc}
\hline Parent phase & $\begin{array}{c}\text { Sintering time } \\
(\text { min })\end{array}$ & $\begin{array}{c}\text { Threshold } \\
\text { TiC vol. }\left(\varphi_{\mathrm{c}}\right)\end{array}$ & Value of ' $t$ ' \\
\hline $\mathrm{ZrO}_{2}$ & 10 & $31 \cdot 2$ & 0.52 \\
& 90 & $33 \cdot 5$ & $0 \cdot 10$ \\
$\mathrm{Al}_{2} \mathrm{O}_{3}$ & 180 & $34 \cdot 0$ & $1 \cdot 78$ \\
\hline
\end{tabular}

cal (percolation) volume fraction for the high conductivity phase and $t$ the resistivity exponent whose values range between 1.65 and 2.00 (Balberg 1987).

Equation (1) can be written as

$$
\log \rho_{\mathrm{m}}=\log k+t \log \left\{(1-\varphi) / \varphi_{\mathrm{c}}\right\},
$$

where $k$ is the proportionality constant.

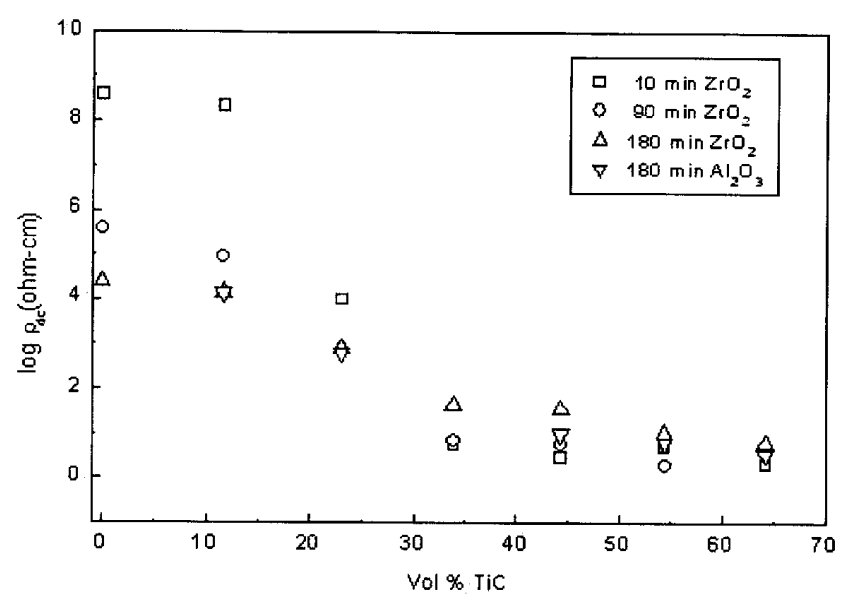

Figure 3. Variation of d.c. resistivity of $\mathrm{Al}_{2} \mathrm{O}_{3}$ and $\mathrm{ZrO}_{2}$ composites with $\mathrm{TiC}$.

The compositions of the matrix for microstructural studies were so selected that they are close to the threshold of the critical percolation volume of the systems to have an idea of the matrix. The threshold volume for such percolation in the systems are, however, dependent on the grain size and amount of the parent and the conducting second phases, shape, size and amount of the pores present in the matrix. The value of $\varphi_{c}$ seems to be on the higher side in both cases mainly because of the larger particle size of the conducting phase and the presence of pores in the matrix (table 2).

\section{Conclusions}

(I) $\mathrm{TiC}$ was of no help in sintering of alumina and zirconia at $1600^{\circ} \mathrm{C}$. Sintered density of alumina, however, increased while that of zirconia decreased with addition of TiC.

(II) The minimum percolation volume of $\mathrm{TiC}$ in $180 \mathrm{~min}$ sintered alumina was $26.3 \mathrm{vol} \%$ and that of zirconia, 34.0 vol. $\%$. This volume decreased when the composites were sintered for shorter time because of non-coagulation of $\mathrm{TiC}$ and finer $\mathrm{Al}_{2} \mathrm{O}_{3}$.

(III) The d.c. resistivity of both composites were sufficiently low and there is a possibility of machining them by EDM technique as addition of $30 \mathrm{vol} \% \mathrm{TiC}$ also improves mechanical properties of the sintered composites, in general.

\section{Acknowledgements}

The work was carried out at the Non-Oxide Ceramic Section, Central Glass and Ceramic Research Institute, Kolkata. The authors are grateful to all the staff members of the section. The authors are also grateful to the Director, CGCRI, Kolkata, for providing facilities. 


\section{References}

Balberg I 1987 Phys. Rev. Lett. 1305

Bellosi A et al 1989 Electroconductive $\mathrm{Si}_{3} \mathrm{~N}_{4}$ based composites, Euroceramics (ed.) G de with (London: Elsevier Applied Sci.), Vol 3, pp 3·389-93

Buerger W 1994 Keram Z. 46 547, 550

Guicciardi B.de portu 1992 J. Euro. Ceram. Soc. 10307

Krell A, Blank P, Pippel E and Woltersdorf J 1995 J. Am. Ceram. Soc. 782641

Mao D S, Liu X H, Li J, Guo S Y, Zhang X B and Mao Z Y 1998 J. Mater. Sci. 335677

Matkin D I, Cavell I W and Dyson J R 1972 Proc. Br. Ceram. Soc. 2358
Mclachlan D S 1988 J. Phys. C: Solid State Phys. C21 1521

Mclachlan D S, Blaszkiewicz M and Newnham R E $1990 \mathrm{~J}$. Am. Ceram. Soc. 732187

Nakayama S and Kuroshima H 1992 J. Ceram. Soc. Japan 100 758

Pierson H O 1996 Handbook of refractory carbides and nitrides (USA: Noyes Publ.)

Sawaguchi A, Toda K and Niihara K 1991 J. Am. Ceram. Soc. 741142

Wang H L, Li J B, Li Y and Liu J F 1999 Study of electrical conductivity of $\mathrm{TiC} / \mathrm{Si}_{3} \mathrm{~N}_{4}$ ceramic composite, Proc. 1st China conf. on high performance ceramics, Beijing, (ed.) D S Yan and Z D Guan (Beijing: Tsinghua University Press) p. 432 